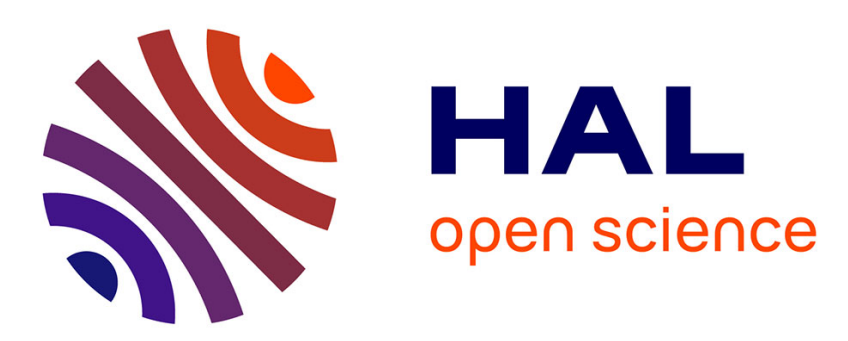

\title{
Impact of disease activity and treatments on ovarian reserve in patients with rheumatoid arthritis in the ESPOIR cohort
}

\author{
Camille Valdeyron, Martin Soubrier, Bruno Pereira, Arnaud Constantin, \\ Jacques Morel, Philippe Gaudin, Bernard Combe, Anne Sophie Gremeau, \\ Lydie Dejou-Bouillet, Jean Luc Pouly, et al.
}

\section{To cite this version:}

Camille Valdeyron, Martin Soubrier, Bruno Pereira, Arnaud Constantin, Jacques Morel, et al.. Impact of disease activity and treatments on ovarian reserve in patients with rheumatoid arthritis in the ESPOIR cohort. Rheumatology, 2020, 10.1093/rheumatology/keaa535 . hal-03040700

\author{
HAL Id: hal-03040700 \\ https://hal.science/hal-03040700
}

Submitted on 8 Dec 2020

HAL is a multi-disciplinary open access archive for the deposit and dissemination of scientific research documents, whether they are published or not. The documents may come from teaching and research institutions in France or abroad, or from public or private research centers.
L'archive ouverte pluridisciplinaire HAL, est destinée au dépôt et à la diffusion de documents scientifiques de niveau recherche, publiés ou non, émanant des établissements d'enseignement et de recherche français ou étrangers, des laboratoires publics ou privés. 
Impact of disease activity and treatments on ovarian reserve in patients with rheumatoid arthritis in the ESPOIR cohort.

Camille Valdeyron ${ }^{1}$, Martin Soubrier ${ }^{2}$, Bruno Pereira ${ }^{3}$, Arnaud Constantin ${ }^{4}$, Jacques $^{-}$ Morel $^{5}$, Philippe Gaudin 6 , Bernard Combes, Anne Sophie Gremeau', Lydie DejouBouillet $^{1}$, Jean Luc Pouly ${ }^{1}$, Vincent Sapin ${ }^{7}$, Charlotte Oris ${ }^{7}$, Florence Brugnon ${ }^{8}$

${ }^{1}$ Reproductive Health Center, Estaing Hospital, CHU Clermont-Ferrand, France

${ }^{2}$ Rheumatology, CHU Gabriel-Montpied, Clermont-Ferrand University France

${ }^{3}$ Biostatistics Unit (DRCI), CHU Clermont-Ferrand, France

${ }^{4}$ Rheumatology, CHU Purpan, Toulouse University, France

${ }^{5}$ Rheumatology, CHU Montpellier, Montpellier University, France

${ }^{6}$ Rheumatology, Sud Echirolles Hospital, CHU Grenoble Alpes, France

${ }^{7}$ Biochemistry and Molecular Genetic, CHU Clermont-Ferrand, France

${ }^{8}$ UCA, IMoST - INSERM 1240- Faculty of medecine, Clermont-Ferrand University, France

Corresponding author: Pr Florence BRUGNON

Developmental Biology and Reproduction: ART, CHU Estaing

1 place Lucie AUBRAC, F-63000, Clermont-Ferrand, France fbrugnon@chu-clermontferrand.fr; ORCID iD: 0000-0002-8402-8734; 


\section{Abstract:}

Objectives: Patients with rheumatoid arthritis (RA) have a higher prevalence of infertility than the general population. This study sought to examine the impact of RA disease activity and treatments on ovarian reserve measured by serum anti-Müllerian hormone (AMH) levels in the ESPOIR cohort. We sought to better define the indications for fertility preservation.

Methods: Patients and serum analysis data were derived from the French national cohort ESPOIR. Enrolled patients ( $\mathrm{n}=102 ; 18$-37-year-olds) fulfilled ACR/EULAR2010 criteria for RA. Serum AMH levels were measured at T0, T6, T12, T24, and T36 months post-diagnosis. The impacts of RA activity (DAS28 and CRP level) and treatments (methotrexate only or with other medications) were evaluated at each study visit.

Results: A gradual decrease in patients' serum AMH levels was observed over time, in line with the descending curve described for healthy women. Serum AMH levels of RA patients in comparison with the values considered normal for age did not reveal any significant differences $(P>0.05)$. We did not observe any impact of RA treatments. We demonstrated an inverse correlation between AMH variation and disease activity (DAS28: $\mathrm{r}=-0.27, P=$ 0.003; CRP: $\mathrm{r}=-0.16, P=0.06)$.

Conclusion: This is the first study to determine serum AMH levels of a large cohort of RA patients over 36 months. Rapid disease activity control appears to be required to limit changes in the ovarian reserve. Fertility preservation is not likely to be necessary if inflammation is promptly controlled.

\section{Key messages:}

- There is an adverse impact of RA activity on serum AMH levels.

- Rapid disease activity limitation appears to be required to limit changes in the ovarian reserve.

- Fertility preservation for RA women seems not to be necessary if inflammation is promptly controlled.

\section{Key words:}

Rheumatoid Arthritis/ Inflammation/ Fertility/ Woman/ Methotrexate/ Ovarian Reserve/ AMH/ DAS28/ Disease Activity.

Clinical Trial ESPOIR cohort: NCT03666091. 


\section{Introduction}

Rheumatoid arthritis (RA) may affect the fertility of women suffering from this pathology [16)]. Recent studies have shown unexplained infertility (7), with longer mean time to pregnancy (8-11), higher prevalence of dysovulation (12,13), nulliparous women (14), and reduced ovarian reserve $(12,15)$ compared with the general population. However, it is not clear if these women's subfertility is due to RA activity and/or their treatments. Ovarian reserve can be evaluated by measuring the serum anti-Müllerian hormone (AMH) level. AMH is a hormone produced by granulosa cells surrounding oocytes in growing follicles that have undergone recruitment in the ovary (16-18). Serum AMH level is considered to be an accurate biomarker of ovarian reserve, capable of reflecting the size of the ovarian follicular pool at reproductive age (19-21). The value of this biomarker is not influenced by the period of the menstrual cycle and will reflect an early reduction of the ovarian follicle reserve (22). To mitigate the decrease in follicle reserve linked to gonadotoxic treatment or disease, fertility preservation is currently possible for these women through the cryopreservation of oocytes and/or ovarian tissue (23). When needed, the thawed oocytes may be used for assisted reproductive technology by intra-cytoplasmic sperm injection, and ovarian tissue may be grafted if infertility is confirmed. Recent studies reporting the impact of RA and its treatment on fertility were performed with a short time of follow-up (24) or only small patient cohort sizes $(25,26)$. Hence, there is no consensus in the literature on indications of fertility preservation for these patients regarding RA activity and the treatments they receive.

The aim of our study was to examine the impact of RA activity and its related treatments on ovarian reserve measured by serum AMH level in a large cohort of patients for 36 months. 
The information obtained in this analysis may help to better define indications of fertility preservation for these patients.

\section{Patients and Methods}

\section{Patients}

Patient data and blood sample analyses were obtained from the French prospective multicentred observational cohort ESPOIR (27) (Etude et Suivi des Polyarthrites Indifférenciées Récentes) sponsored by the French Society of Rheumatology (FSR), in December 2002. The ESPOIR cohort is a French database for various investigations (diagnostic, prognostic, economics, etc.). The study included 813 patients aged 18-70 years with early arthritis and attending 14 rheumatology centres in France between December 2002 and April 2005. To be included, patients had to have RA present for less than 6 months before inclusion or undifferentiated inflammatory arthritis (UA) with potential for developing RA, also for less than 6 months. UA is early arthritis that does not meet the criteria for another diagnosis, such as erythema nodosum or sacroiliitis, or that has joint characteristics and extraarticular characteristics incompatible with RA.

All the patients recruited in the ESPOIR cohort were naive to any treatment at inclusion. Only anti-inflammatory medication taken for less than 15 days before inclusion was allowed. Patients were followed up by the same investigator every 6 months for 2 years and every year for at least 10 years. The protocol of the ESPOIR cohort was approved by the ethics committee of Montpellier, France (no. 020307). All the patients gave their signed informed consent before inclusion. One biological resources centre (Sarah Tubiana, Paris-Bichat) was in charge of centralising and managing biological data collection. 
In our study, we enrolled women $(n=102) 18-37$ years old who fulfilled the 2010 American College of Rheumatology/European League Against Rheumatism criteria for RA. Fifteen women without treatment who were considered to have undifferentiated arthritis (UA) with the potential to become RA and were used as a chronic inflammatory disorder control group. This group allowed us to analyse the impact of inflammation itself on ovarian reserve without confounding by any potential effect of treatment. We excluded men, and women under the age of 18 and over 37 years old. We chose the age limit of 37 years because the serum AMH level decreases significantly and physiologically at this age due to follicular atresia (18).We also excluded patients with ovarian surgery and premature ovarian insufficiency (POI) defined, according to the ESHRE guideline (28) on the management of POI 2015, by loss of ovarian activity before the age of 40 years. POI is characterized by menstrual disturbance (amenorrhea or oligomenorrhea) with raised gonadotropins and low estradiol.

\section{Measurements}

The primary outcome was the global evolution of the serum AMH level (ng/mL), adjusted for age, over 36 months of follow-up in patients with RA. The measurement of AMH level was performed using the electrochemiluminescence method with a Cobas ${ }^{\circledR}$ e411 analyser (Roche Diagnostics, Meylan, France). The threshold of $<1 \mathrm{ng} / \mathrm{mL}$ was considered to be a proof of severe decrease in ovarian reserve. The serum AMH assay was performed on patients from the ESPOIR cohort at baseline (T0), 6, 12, 24, and 36 months after inclusion (T6, T12, T24, and T36, respectively). All the results were expressed as the median value of AMH level (ng/mL). Blood samples were available for 117 patients at T0, 111 at T6, 106 at T12, 99 at T24, and 82 at T36 months of follow-up.

We analysed the impact of RA activity and inflammation on the serum AMH level. Disease activity was scored using the Disease Activity Score in 28 joints (DAS28 CRP) and biological parameters of inflammation: C-reactive protein in $\mathrm{mg} / \mathrm{L}$ (CRP) and erythrocyte sedimentation 
rate in $\mathrm{mm} / \mathrm{h}$ (ESR). Anti-CCP antibodies were measured from thawed frozen sera using Immunoscan CCplus®, Eurodiagnostica, Arnhem, The Nederlands.

Finally, we evaluated the potential impact of treatments used on AMH level. The treatments used were methotrexate (MTX) only or with other treatments. The focus on MTX was justified by its high frequency of use because it is the first line of treatment used in RA according to the EULAR and SFR recommendations (29) (30). To study the potential effects of the treatments, we analysed four groups of patients according to their treatment (Fig. 2): MTX only $(\mathrm{n}=27)$, MTX and other treatments $(\mathrm{n}=56)$ (hydroxychloroquine, leflunomide, sulfasalazine, etanercept, adalimumab, rituximab, and infliximab), treatment without MTX (n = 19) (leflunomide, sulfasalazine, and hydroxychloroquine), and a control group without treatment $(\mathrm{n}=15)$. We also studied the impact of corticosteroid on AMH level, with 69 exposed patients and 37 patients without corticosteroid treatment.

\section{Statistical analysis}

Statistical analyses were performed using Stata software (version 13, StataCorp, College Station, US). All tests were two-sided, with a Type I error set at 0.05. Continuous data were expressed as median (interquartile range) according to the statistical distribution. The assumption of normality was assessed using the Shapiro-Wilk test.

Concerning baseline data, the comparisons were conducted using (i) chi-square and Fisher's exact tests, as appropriate, for categorical data, and (ii) analysis of variance (ANOVA), or the Kruskal-Wallis test when the assumptions of ANOVA were not met, for continuous parameters. When appropriate (omnibus $P$-value less than 0.05 ), a post-hoc test for multiple two-by-two comparisons was performed: Tukey-Kramer after ANOVA and Dunn post Kruskal-Wallis. To study the relationships between continuous parameters, Pearson or Spearman correlation coefficients were estimated. Random-effects models (more precisely, linear mixed models) were performed to compare the evolution of the AMH level between 
treatment groups, (i) studying the following fixed effects: group, time-points, and their interaction, and (ii) taking into account the between-and within-patient variability (considering the subjects as random-effect). Sidak's type I error correction was applied to perform multiple comparisons. The normality of residuals was analysed using the ShapiroWilk test and a logarithmic transformation of the AMH level was then conducted to assess the normality. Multivariable analyses were then carried out with adjustment for age and DAS28 at inclusion, as the treatment groups differed in these parameters at inclusion. A sensitivity analysis was performed, considering the $\mathrm{AMH}$ level as a normal/non-normal dichotomous parameter. The age-related threshold reported in the literature was applied. To compare the evolution of the AMH level between treatment groups, a generalized linear mixed model with a logit link function was used. 


\section{Results}

\section{Baseline demographics and disease activity}

Study population details are shown in Table 1. In all, 117 women from the ESPOIR cohort were included. They were 29.9 (24.8-33.5) years old. Among these enrolled women, 102 (90\%) fulfilled the 2010 ACR/EULAR RA classification criteria and were diagnosed as RA patients. They began their treatment on the day of inclusion (T0). Fifteen (10\%) women, diagnosed as having UA without treatment, were included in the chronic inflammatory disorder control group. These women were 28.2 (25.0-33.8) years old.

Median body mass index (BMI) was $22.2(20.5-25.0) \mathrm{kg} / \mathrm{m}^{2}$. Sixty-seven patients $(51 \%)$ were smokers. As shown in Table 1, there were no differences in these characteristics between the evaluated patients and the control group.

Rheumatoid factor (RF) was positive in $43(33 \%)$ patients and anti-citrullinated protein antibodies (ACPA) were positive in $45(35 \%)$ patients. There was a significant difference in both these parameters between the subgroup of patients treated with MTX and the other groups without MTX ( $\mathrm{p}<0.05)$. There was no difference in serum AMH level between patient with ACPA-positive patients and ACPA-negative patients, with respective values of 1.52 $(0.63-3.26) \mathrm{ng} / \mathrm{mL}$ and $1.72(0.97-2.81) \mathrm{ng} / \mathrm{mL}(P=0.64)$. The median serum CRP level was $10(5-24) \mathrm{mg} / \mathrm{L}$ and the median ESR level was $20(10-35) \mathrm{mm} / \mathrm{h}$. There was no significant difference in CRP and ESR levels at T0 between any groups of patients.

The patients' median value of DAS28 was 5.0 (4.3-5.8), corresponding to moderate disease activity. The DAS28 score of the subgroup of patients treated with MTX was higher at 5.5(4.5-6.2) corresponding to high RA activity compared with the other groups $(P=0.001)$, and a higher level of inflammation and disease activity for these patients. The Health 
Assessment Questionnaire (HAQ) score was significantly higher in the MTX group $(1.25[0.88-1.63])$ compared with the other groups $(P<0.02)$.

\section{Impact of disease activity and inflammation on serum AMH level}

The analysis of serum AMH level over the time and as function of age describes a gradual decrease (Fig. 1). There was no significant difference between AMH level at T12, T24, and T36 compared with T0 $(P>0.05)$. We observed a lower AMH level at T0 compared with T6 $(1.70 \mathrm{ng} / \mathrm{mL}$ vs. $2.20 \mathrm{ng} / \mathrm{mL} ; P=0.017)$ in the group of 102 patients with treatment. Control group serum AMH levels measured at the different times during the 36-month follow-up period did not differ significantly.

At T0, the serum AMH level was negatively correlated with the DAS28 score $(\mathrm{r}=-0.12 ; P=$ $0.15)$ and with the biological parameters of inflammation (CRP, $\mathrm{r}=-0.26 ; \mathrm{ESR}, \mathrm{r}=-0.19 ; P$ $=0.002)($ Fig. 3).

There was a statistically significant decrease in RA activity (measured by DAS28 score; $r=-$ $0.28 ; P=0.003$ ) and a trend for inflammation (measured by serum CRP level; $\mathrm{r}=-0.17 ; P=$ 0.06) which was correlated with the increase in AMH level $(1.70 \mathrm{ng} / \mathrm{mL}$ vs. $2.20 \mathrm{ng} / \mathrm{mL})$ between T0 and T6 for all the patients evaluated, whatever treatment they received. The control of inflammation was correlated with an improvement in AMH level. These variations were not observed in the control group $(\mathrm{r}=0, P=0.99)$.

There was no statistical difference between groups regarding the evolution of AMH level between T6, T12 $(P=0.09), \mathrm{T} 24(P=0.35)$, and T36 $(P=0.61)$. 


\section{Impact of treatments on serum AMH level during 36 months of follow-up}

At T0, we found a lower serum AMH level in the "MTX only" patient group $(n=27)$ compared with the "without MTX" patient group $(\mathrm{n}=19 ; P=0.002)$ and the control group (n $=15 ; P>0.05)$. The DAS28 score was higher in the "with MTX" patient group (DAS28 at 5.5 (4.5-6.2)) compared with the "without MTX" patient group (DAS28 at 4.6 [3.8-5.5 ]), $P=0.001$.

Although the mean AMH level tended to decrease during the follow-up, we did not observe a significant difference between the serum AMH levels at T12, T24, and T36 compared with T0 $(P>0.05)$, whatever the treatments (MTX or not) in the patients evaluated, even after adjustment for the DAS28 score. Indeed, the serum AMH level evolved from $1.13 \mathrm{ng} / \mathrm{mL}$ to $1.14 \mathrm{ng} / \mathrm{mL}$ at T36 in the MTX-only group $(\mathrm{n}=27)$, from 1.52 to $1.34 \mathrm{ng} / \mathrm{mL}$ at T36 in the MTX with or without other treatments $(\mathrm{n}=83)$ group, and from $1.72 \mathrm{ng} / \mathrm{mL}$ to $1.62 \mathrm{ng} / \mathrm{mL}$ at T36 in the without MTX group $(\mathrm{n}=19)$, versus from $1.62 \mathrm{ng} / \mathrm{mL}$ to $0.94 \mathrm{ng} / \mathrm{mL}$ in the control group $(\mathrm{n}=15)$ (Fig. 2).

There was no difference in the evolution of the serum AMH level (Fig. 1) over time between RA patients under treatment $(\mathrm{n}=102)$ and the control group $(\mathrm{n}=15 ; P=0.13)$ and between groups of patients who fulfilled $(n=102)$ or did not fulfil $(n=15)$ the ACR/EULAR 2010 criteria $(P>0.05)$.

In regard to corticosteroid treatments, we did not find a difference in serum AMH levels between users $(n=69)$ and non-users $(n=37)$ at any time of the comparison, even with doses higher than $7.5 \mathrm{mg}$ per day $(\mathrm{n}=6)$. 


\section{Discussion}

By following this cohort of women of reproductive age with early RA for a period of 36 months, we were able to clearly show that RA activity was correlated with a decrease in serum AMH level. However, AMH level as a function of age in these patients is similar to the physiological concentration of AMH over time reported by Kelsey et al. (31) in women without RA. In addition, we did not observe any impact of treatments used to treat RA on AMH level of these women.

This study enabled us to show clearly to show the impact of RA activity on serum AMH level early in the disease. This decline in serum AMH level is linked to the decrease in ovarian reserve we observed when diagnosing RA before starting treatment. The strength of our study lies in the size of the ESPOIR cohort and the long follow-up period of 36 months. No previous study has carried out as lengthy a longitudinal follow-up of an equally large number of patients. We were only able to evaluate ovarian reserve on the basis of serum AMH level because ovarian echography had not been performed for the patients included in the study.

The impact of RA on female fertility remains controversial. Henes et al. (25) showed that patients with RA had a lower AMH level, a lower pregnancy rate (Del Junco et al. (1), and a longer waiting time to pregnancy $(8,9)$ compared with the general population. Other authors focused more particularly on the effect of MTX, since it is a first-line treatment for RA. Two studies pointed to a reduction of ovarian reserve after exposure to $\operatorname{MTX}(31,32)$. Nonetheless, these observations were not confirmed by Brouwer et al. (24) in a follow-up of RA patients over a 6-months period of exposure to MTX. A similar result was observed in a recent study of Eudy et al. in 2019 (7), with no impact of MTX on AMH level. In our study, we did not find an impact of MTX during the 36-month follow-up period in the patients exposed only to MTX $(n=27)$ or in those exposed to MTX in addition to other treatments $(n=56)$. The 
diversity of groups of treatments in our study is explained by the fact that the cohort of patients is multicentred and by the difficulty of clearly determining the diagnosis of RA in the framework of early arthritis. Such diagnosis involves a variety of recommendations and diverse clinical rheumatologic practices, as shown by Benhamou et al. (34). This likely explains our study's possible lack of power in its evaluation of the effects of treatments, due to the lower number of patients in each group after adjustment. However, it is noteworthy that a large proportion of the treatments used are not known to affect fertility - this reduces the risk of interference in the interpretation of our results with, in particular, leflunomide, hydroxychloroquine, and sulfasalazine. Only a severe impact would justify preserving fertility. Our study therefore confirms results published previously that do not recommend preserving fertility for patients undergoing treatment with immunosuppressive doses of MTX (35). However, it is important to note that since the formation of this cohort new and effective RA treatments have been developed. It will be interesting to analyse the impact of new generation of treatments on $\mathrm{AMH}$ in a further study.

Regarding corticosteroid therapy, no significant difference in serum AMH level was observed between the exposed and unexposed patients. This observation does not confirm the data in the literature. Brouwer et al. (9) highlighted a link between corticosteroid therapy and a reduction in fertility in $66 \%$ of the 245 women in the Pregnancy-Induced Amelioration of RA (PARA) cohort composed of patients following corticosteroid therapy at a dose of 7.5 $\mathrm{mg}$ /day. When patients followed corticosteroid therapy at a dose higher than this daily dose, an increase in the waiting time to pregnancy was observed in comparison with a control group. In our study, the number of patients exposed to this dose was very low, which perhaps explains the observed absence of difference.

The analysis of AMH levels according to ACPA status did not show any significant difference contrary to the previous study in 2019 by Brouwer et al. (36) which demonstrated 
lower AMH levels in ACPA-positive patients compared with healthy women as a control group. In our study the control group consisted of patients with UA. Moreover, we applied the same assay to measure serum AMH level in patients and control groups. This may explain this lack of difference in our study.

No correlation was found in previous studies between serum inflammatory parameters, disease activity, and AMH level. Brouwer et al. (36) did not show any association between disease activity and serum AMH level in a recent study. However, their study was based on a population whose disease activity was under control and who had participated in a pregnancy project. Our study clearly shows a correlation between RA activity and AMH level. At inclusion, inflammation linked to RA was not controlled by treatment, with RA activity evaluated as moderate or high as a function of group, according to the DAS28 score. The organisation of treatment from the time of diagnosis of RA makes it possible to see its probable beneficial impact on disease evolution at 6 months, with a significant improvement in serum AMH level whatever the treatment group. An increased prevalence of infertility of unknown aetiology was shown by Brouwer et al. (12) in these patients. Our data appear to show that it might be an effect of inflammation on the ovarian reserve.

RA activity, which reflects the magnitude of articular inflammation, generally appears to have a significant impact on serum AMH level. Previously, it was only possible to draw a link between increased waiting time to pregnancy and the inflammatory activity of RA (3). The hypothesis used to explain this association was potential sexuality disorders linked to a fall in libido related to inflammation-induced pain. Pikwer et al. showed an association between the occurrence of the menopause before the age of 45 and the development of RA, with an odds ratio (OR) of 2.42, 95\% CI 1.32 to 4.45 (37). The authors hypothesized a link between the inflammation present before the diagnosis and the reduction of ovarian reserve, leading to premature menopause. The same observation was made by Del Junco et al., who 
demonstrated that female fertility was reduced before the diagnosis of RA was made (1). In our study also, it was at T0 that we found the lowest AMH level. In comparison with other models of chronic systemic diseases such as Crohn's disease, it has been shown that serum $\mathrm{AMH}$ values are also clearly reduced in patients with intense disease activity compared with a control group of patients in remission (36). Inflammation therefore appears to play a crucial role in fertility in RA.

Indeed, proinflammatory cytokines such as interleukin (IL) and TNF $\alpha$ can harm the vascular system, possibly explaining the link between the inflammatory activity of a disease and damage to the ovarian reserve $(35,37)$. Paradisi et al. (39) studied the potential link between cytokines and the ovarian reserve in patients with Hodgkin's and non-Hogkin's lymphoma before the administration of chemotherapy. A negative correlation was found between AMH level and IL6 in these patients (39). In an animal model, IL-1 was implicated in the regulation of the ovarian reserve through an increase of serum AMH level, with a better response of the ovaries to gonadotropins in IL-1-beta-deficient mice (40). It would therefore be interesting to extend our study by measuring cytokine levels in the serum and/or follicular fluid to analyse their potential influence and better understand how inflammation affects the ovarian reserve of patients with RA. One might imagine that reducing inflammation would remove this "shock" to the production of AMH by the granulosa cells. Accordingly, it would be interesting to know whether the granulosa cells can be destroyed by long exposure to inflammation (driven by cytokines), since that would clearly link inflammation to a reduced ovarian reserve.

In conclusion, our study highlights the harmful impact of RA activity on the serum AMH level, an indicator of the ovarian reserve. We did not demonstrate the impact of treatments. Our study therefore tends to show that patients with RA do not need to preserve their fertility. Nevertheless, it appears important to thoroughly control the inflammatory activity of RA from 
the time it is considered as a diagnosis, in order to limit the premature impact of inflammation on the ovarian reserve. In the future, it would be interesting to measure interleukin levels in follicular fluid to better understand the physiopathology of the damage incurred. 


\section{Acknowledgements:}

An unrestricted grant from Merck Sharp and Dohme was allocated for the first 5 years. Two additional grants from INSERM were obtained to support part of the biological database. The French Society of Rheumatology, Pfizer, Abbvie, and Lilly also supported the ESPOIR cohort study. We also wish to thank Nathalie Rincheval (CHU Montpellier and EA 2415) who did expert monitoring and data management, and all the investigators who recruited and followed the patients (F. Berenbaum, Paris-Saint Antoine; M.C. Boissier, Paris-Bobigny; A. Cantagrel, Toulouse; B. Combe, Montpellier; M. Dougados, Paris-Cochin; P. Fardellone and P. Boumier, Amiens; B. Fautrel, Paris-La Pitié; R.M. Flipo, Lille; Ph. Goupille, Tours; F. Liote, Paris-Lariboisière; O. Vittecoq, Rouen; X. Mariette, Paris Bicetre; P. Dieude, Paris Bichat; A. Saraux, Brest; T. Schaeverbeke, Bordeaux; and J. Sibilia, Strasbourg). We finally wish to thank A. Vega and C.Lambert (Biostatistics Unit (DRCI)), CHU Clermont-Ferrand for our contribution. This work was supported by Roche Diagnostics with the generous gift of the AMH assays.

\section{Conflicts of interest}

No conflicts of interest. 


\section{References}

1. Del Junco DJ, Annegers JF, Coulam CB, Luthra HS. The relationship between rheumatoid arthritis and reproductive function. Br J Rheumatol. 1989;28 Suppl 1:33; discussion 42-45.

2. Provost M, Eaton JL, Clowse MEB. Fertility and infertility in rheumatoid arthritis. Curr Opin Rheumatol. 2014;26(3):308-14.

3. Ostensen M. Rheumatoid arthritis: The effect of RA and medication on female fertility. Nat Rev Rheumatol. 2014;10(9):518-9.

4. Kay A, Bach F. subfertility before and after the development of rheumatoid arthritis in women. Ann Rheum Dis. 1965;24:169-73.

5. Katz PP. Childbearing decisions and family size among women with rheumatoid arthritis. Arthritis Rheum. 2006;55(2):217-23.

6. Østensen M. New insights into sexual functioning and fertility in rheumatic diseases. Best Pract Res Clin Rheumatol. 2004;18(2):219-32.

7. Eudy AM, McDaniel G, Hurd WW, Clowse MEB. Fertility and Ovarian Reserve among Women with Rheumatoid Arthritis. J Rheumatol. 2019;46(5):455-9.

8. Clowse MEB, Chakravarty E, Costenbader KH, Chambers C, Michaud K. Effects of infertility, pregnancy loss, and patient concerns on family size of women with rheumatoid arthritis and systemic lupus erythematosus. Arthritis Care Res. 2012;64(5):668-74.

9. Brouwer J, Hazes JMW, Laven JSE, Dolhain RJEM. Fertility in women with rheumatoid arthritis: influence of disease activity and medication. Ann Rheum Dis. 2015;74(10):1836-41.

10. Nelson JL, Koepsell TD, Dugowson CE, Voigt LF, Daling JR, Hansen JA. Fecundity before disease onset in women with rheumatoid arthritis. Arthritis Rheum. 1993;36(1):7-14.

11. Jawaheer D, Zhu JL, Nohr EA, Olsen J. Time to pregnancy among women with rheumatoid arthritis. Arthritis Rheum. 2011;63(6):1517-21.

12. Brouwer J, Fleurbaaij R, Hazes JMW, Dolhain RJEM, Laven JSE. Subfertility in rheumatoid arthritis is often unexplained or caused by anovulation. Arthritis Care Res. 2016;

13. Flaisler F, Hedon B, Sany J, Combe B. A study of ovarian function in rheumatoid arthritis. Rev Rhum Engl Ed.1995;62(9):549-54.

14. Wallenius M, Skomsvoll JF, Irgens LM, Salvesen KÅ, Nordvåg B-Y, Koldingsnes W, et al. Fertility in women with chronic inflammatory arthritides. Rheumatol Oxf Engl. 2011;50(6):1162-7.

15. Anasti JN. Premature ovarian failure: an update. Fertil Steril. 1998;70(1):1-15.

16. Durlinger ALL, Visser JA, Themmen APN. Regulation of ovarian function: the role of antiMüllerian hormone. Reprod Camb Engl. 2002;124(5):601-9.

17. La Marca A, Pati M, Orvieto R, Stabile G, Carducci Artenisio A, Volpe A. Serum antimüllerian hormone levels in women with secondary amenorrhea. Fertil Steril. 2006;85(5):1547-9.

18. La Marca A, Sighinolfi G, Giulini S, Traglia M, Argento C, Sala C, et al. Normal serum concentrations of anti-Müllerian hormone in women with regular menstrual cycles. Reprod Biomed 
Online. 2010;21(4):463-9.

19. Tehrani FR, Solaymani-Dodaran M, Azizi F. A single test of antimullerian hormone in late reproductive-aged women is a good predictor of menopause. Menopause N Y N. 2009;16(4):797-802.

20. de Vet A, Laven JSE, de Jong FH, Themmen APN, Fauser BCJM. Antimüllerian hormone serum levels: a putative marker for ovarian aging. Fertil Steril. 2002;77(2):357-62.

21. Sermondade N, Sonigo C, Sifer C, Valtat S, Ziol M, Eustache F, et al. Serum antimüllerian hormone is associated with the number of oocytes matured in vitro and with primordial follicle density in candidates for fertility preservation. Fertil Steril. 2019;111(2):357-62.

22. Ferté-Delbende C, Catteau-Jonard S, Barrière P, Dewailly D. [Evaluation of the ovarian reserve]. J Gynecol Obstet Biol Reprod (Paris). 2010;39(8 Suppl 2):S27-33.

23. Shapira M, Raanani H, Barshack I, Amariglio N, Derech-Haim S, Marciano MN, et al. First delivery in a leukemia survivor after transplantation of cryopreserved ovarian tissue, evaluated for leukemia cells contamination. Fertil Steril. 2018;109(1):48-53.

24. Brouwer J, Laven JSE, Hazes JMW, Schipper I, Dolhain RJEM. Levels of serum antiMüllerian hormone, a marker for ovarian reserve, in women with rheumatoid arthritis. Arthritis Care Res. 2013;65(9):1534-8.

25. Henes M, Froeschlin J, Taran FA, Brucker S, Rall KK, Xenitidis T, et al. Ovarian reserve alterations in premenopausal women with chronic inflammatory rheumatic diseases: impact of rheumatoid arthritis, Behçet's disease and spondyloarthritis on anti-Müllerian hormone levels. Rheumatol Oxf Engl. 2015;54(9):1709-12.

26. Brouwer J, Laven JSE, Hazes JMW, Schipper I, Dolhain RJEM. Levels of serum antiMüllerian hormone, a marker for ovarian reserve, in women with rheumatoid arthritis. Arthritis Care Res. 2013;65(9):1534-8.

27. Combe B, Rincheval N. Early lessons from the recent-onset rheumatoid arthritis cohort ESPOIR. Jt Bone Spine Rev Rhum. 2015;82(1):13-7.

28. Webber L, Davies M, Anderson R, Bartlett J, Braat D, Cartwright B, et al. ESHRE Guideline: management of women with premature ovarian insufficiency. Hum Reprod Oxf Engl. 2016;31(5):926-37.

29. Gaujoux-Viala C, Gossec L, Cantagrel A, Dougados M, Fautrel B, Mariette X, et al. Recommendations of the French Society for Rheumatology for managing rheumatoid arthritis. Jt Bone Spine Rev Rhum. 2014;81(4):287-97.

30. Smolen JS, Landewé R, Bijlsma J, Burmester G, Chatzidionysiou K, Dougados M, et al. EULAR recommendations for the management of rheumatoid arthritis with synthetic and biological disease-modifying antirheumatic drugs: 2016 update. Ann Rheum Dis. 6 mars 2017;

31. Kelsey TW, Wright P, Nelson SM, Anderson RA, Wallace WHB. A validated model of serum anti-müllerian hormone from conception to menopause. PloS One. 2011;6(7):e22024.

32. Jancin. Methotrexate may curb girls' ovarian function. Ann Rheum Dis. 2010;

33. de Araujo DB, Yamakami LYS, Aikawa NE, Bonfá E, Viana VST, Pasoto SG, et al. Ovarian reserve in adult patients with childhood-onset lupus: a possible deleterious effect of methotrexate? Scand J Rheumatol. 2014;43(6):503-11. 
34. Benhamou M, Rincheval N, Roy C, Foltz V, Rozenberg S, Sibilia J, et al. The gap between practice and guidelines in the choice of first-line disease modifying antirheumatic drug in early rheumatoid arthritis: results from the ESPOIR cohort. J Rheumatol. 2009;36(5):934-42.

35. Choux C, Cavalieri M, Barberet J, Samson M, Bonnotte B, Fauque P, et al. [Immunosuppressive therapy and fertility preservation: Indications and methods]. Rev Med Interne. 2018;39(7):557-65.

36. Brouwer J, Dolhain RJEM, Hazes JMW, Visser JA, Laven JSE. Reduced Ovarian Function in Female Rheumatoid Arthritis Patiens trying to conceive. Am Coll Rheumatol. 2019;1(5):327-35.

37. Pikwer M, Bergström U, Nilsson J-Å, Jacobsson L, Turesson C. Early menopause is an independent predictor of rheumatoid arthritis. Ann Rheum Dis. 2012;71(3):378-81.

38. Şenateş E, Çolak Y, Erdem ED, Yeşil A, Coşkunpınar E, Şahin Ö, et al. Serum anti-Müllerian hormone levels are lower in reproductive-age women with Crohn's disease compared to healthy control women. J Crohns Colitis. 2013;7(2):e29-34.

39. Paradisi R, Vicenti R, Macciocca M, Seracchioli R, Rossi S, Fabbri R. High cytokine expression and reduced ovarian reserve in patients with Hodgkin lymphoma or non-Hodgkin lymphoma. Fertil Steril. 2016;106(5):1176-82.

40. Uri-Belapolsky S, Shaish A, Eliyahu E, Grossman H, Levi M, Chuderland D, et al. Interleukin-1 deficiency prolongs ovarian lifespan in mice. Proc Natl Acad Sci U S A. 2014;111(34):12492-7. 
Table 1 Baseline characteristics of the patient population

\begin{tabular}{|c|c|c|c|c|c|}
\hline $\begin{array}{c}\text { Characteristics of } \\
\text { population at } \\
\text { inclusion } \\
\text { (T0) }\end{array}$ & $\begin{array}{l}\text { Total patients } \\
\quad(\mathbf{n}=117)\end{array}$ & $\begin{array}{l}\text { MTX group } \\
\quad(\mathbf{n}=\mathbf{2 7})\end{array}$ & $\begin{array}{c}\text { MTX + other } \\
\text { group } \\
(\mathrm{n}=\mathbf{5 6}) \\
\end{array}$ & $\begin{array}{c}\text { No } \\
\text { MTX group } \\
(n=19)\end{array}$ & $\begin{array}{l}\text { Control } \\
\text { group } \\
(n=15)\end{array}$ \\
\hline $\begin{array}{l}\text { Age } \\
\text { (years) }\end{array}$ & $\begin{array}{c}29.9 \\
(24.8-33.5)\end{array}$ & $\begin{array}{c}31.5 \\
(27.7-34.4)\end{array}$ & $\begin{array}{c}30.1 \\
(24.7-33.6)\end{array}$ & $\begin{array}{c}28.2 \\
(23.9-32.1)\end{array}$ & $\begin{array}{c}28.2 \\
(25.0-33.8)\end{array}$ \\
\hline $\begin{array}{l}\text { BMI } \\
\left(\mathrm{kg} / \mathrm{m}^{2}\right)\end{array}$ & $\begin{array}{c}22.2 \\
(20.5-25.0)\end{array}$ & $\begin{array}{c}23.6 \\
(20.6-25.5)\end{array}$ & $\begin{array}{c}22.2 \\
(20.4-24.5)\end{array}$ & $\begin{array}{c}21.9 \\
(21.0-25.0)\end{array}$ & $\begin{array}{c}25.5 \\
(19.4-28.0)\end{array}$ \\
\hline $\begin{array}{l}\text { Smokers, } \\
\text { n (\%) }\end{array}$ & $67(51 \%)$ & $12(44 \%)$ & $29(52 \%)$ & $8(42 \%)$ & $9(60 \%)$ \\
\hline $\begin{array}{l}\text { RF positivity, } \\
\text { n (\%) }\end{array}$ & $43(33 \%)$ & $11(40 \%)$ & $26(46 \%)$ & $4(21 \%)$ & $0(0 \%)$ \\
\hline $\begin{array}{l}\text { ACPA positivity, } \\
(\%)\end{array}$ & $45(35 \%)$ & $15(55 \%)$ & $25(44 \%)$ & $2(10 \%)$ & $0(0 \%)$ \\
\hline $\begin{array}{l}\text { CRP } \\
(\mathrm{mg} / \mathrm{L})\end{array}$ & $\begin{array}{c}10 \\
(5-24)\end{array}$ & $\begin{array}{c}11 \\
(6-32)\end{array}$ & $\begin{array}{c}10 \\
(4-26)\end{array}$ & $\begin{array}{c}7 \\
(4-18)\end{array}$ & $\begin{array}{c}6 \\
(4-24)\end{array}$ \\
\hline $\begin{array}{l}\text { ESR } \\
(\mathbf{m m} / \mathbf{h})\end{array}$ & $\begin{array}{c}20 \\
(10-35)\end{array}$ & $\begin{array}{c}34 \\
(16-56)\end{array}$ & $\begin{array}{c}18 \\
(10-35)\end{array}$ & $\begin{array}{c}19 \\
(8-25)\end{array}$ & $\begin{array}{c}18 \\
(10-35)\end{array}$ \\
\hline DAS28 & $\begin{array}{c}5.0 \\
(4.3-5.8)\end{array}$ & $\begin{array}{c}5.5 \\
(4.5-6.2)\end{array}$ & $\begin{array}{c}5.0 \\
(4.3-5.8)\end{array}$ & $\begin{array}{c}4.6 \\
(3.8-5.5)\end{array}$ & $\begin{array}{c}3.9 \\
(2.8-4.8)\end{array}$ \\
\hline HAQ & $\begin{array}{c}0.94 \\
(0.50-1.38)\end{array}$ & $\begin{array}{c}1.25 \\
(0.88-1.63)\end{array}$ & $\begin{array}{c}0.88 \\
(0.50-1.50)\end{array}$ & $\begin{array}{c}0.88 \\
(0.5-1.13)\end{array}$ & $\begin{array}{c}0.88 \\
(0.13-1.25)\end{array}$ \\
\hline
\end{tabular}

Abbreviations: MTX, methotrexate; BMI, body mass index; RF, rheumatoid factor; ACPA, anti-citrullinated protein antibodies; DAS28, disease activity score in 28 joints; CRP, $C$ reactive protein; ESR, erythrocyte sedimentation rate; $H A Q$, health assessment questionnaire.

Continuous variables are presented with median $\{\mathrm{IQR}\}$ and categorical parameters variable with number of patients and percentages. 
Fig. 1 Evolution of serum AMH level during 36 months of follow-up according to the age of the patients.

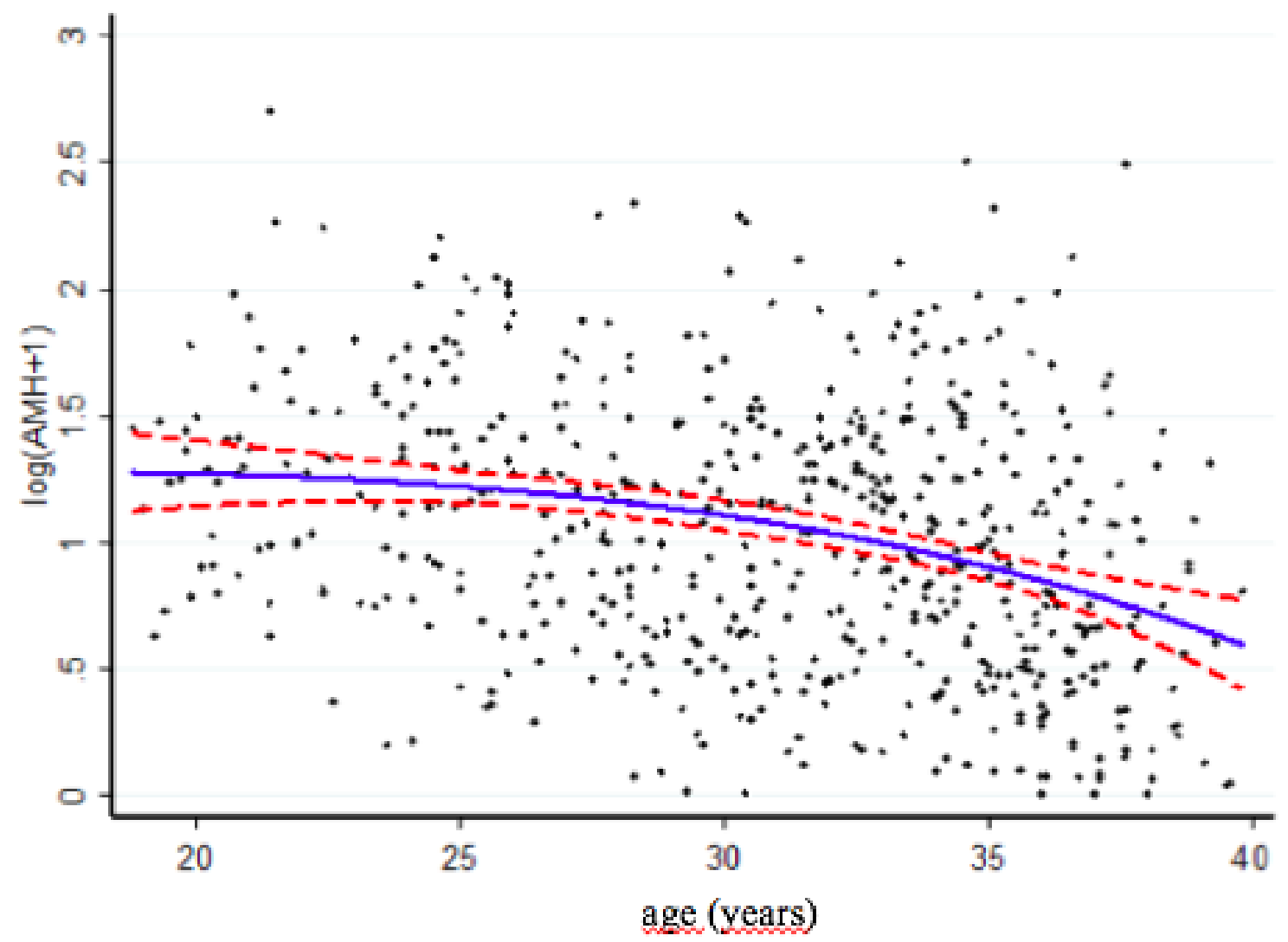

The relationship between age of the patients and serum AMH level was analysed using fractional-polynomial prediction (blue line). Red line corresponds to the 95\% confidence interval. 
Fig. 2 Evolution of serum AMH level for each treatment

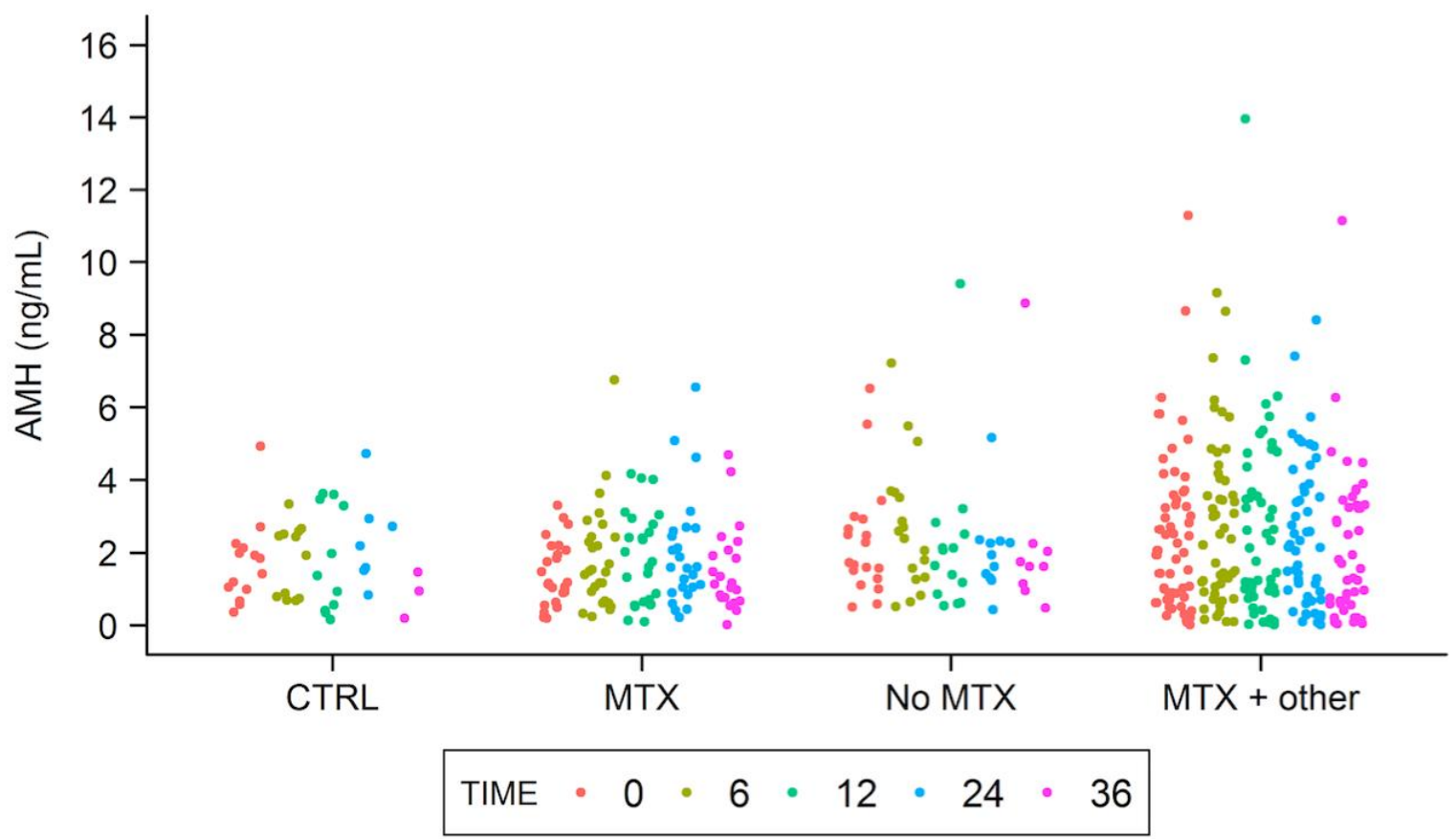

Abbreviations: CTRL, control group; MTX, methotrexate-only group; No MTX, nomethotrexate group; MTX + other, methotrexate-plus-other-treatment group

Serum AMH level according to the treatments received by the patients (MTX: Methotrexate only (n=27), No-MTX: no Methotrexate $(n=19)$, MTX + other: Methotrexate and other treatment $(n=56)$, CTRL : control group $(n=15)$ at different time of evolution of the RA disease (diagnosis: T0; 6 months: T6; 12 months: T12; 24 months: T24 and 36 months: T36). 
Fig. 3 Correlation between serum AMH level and parameter of inflammation :

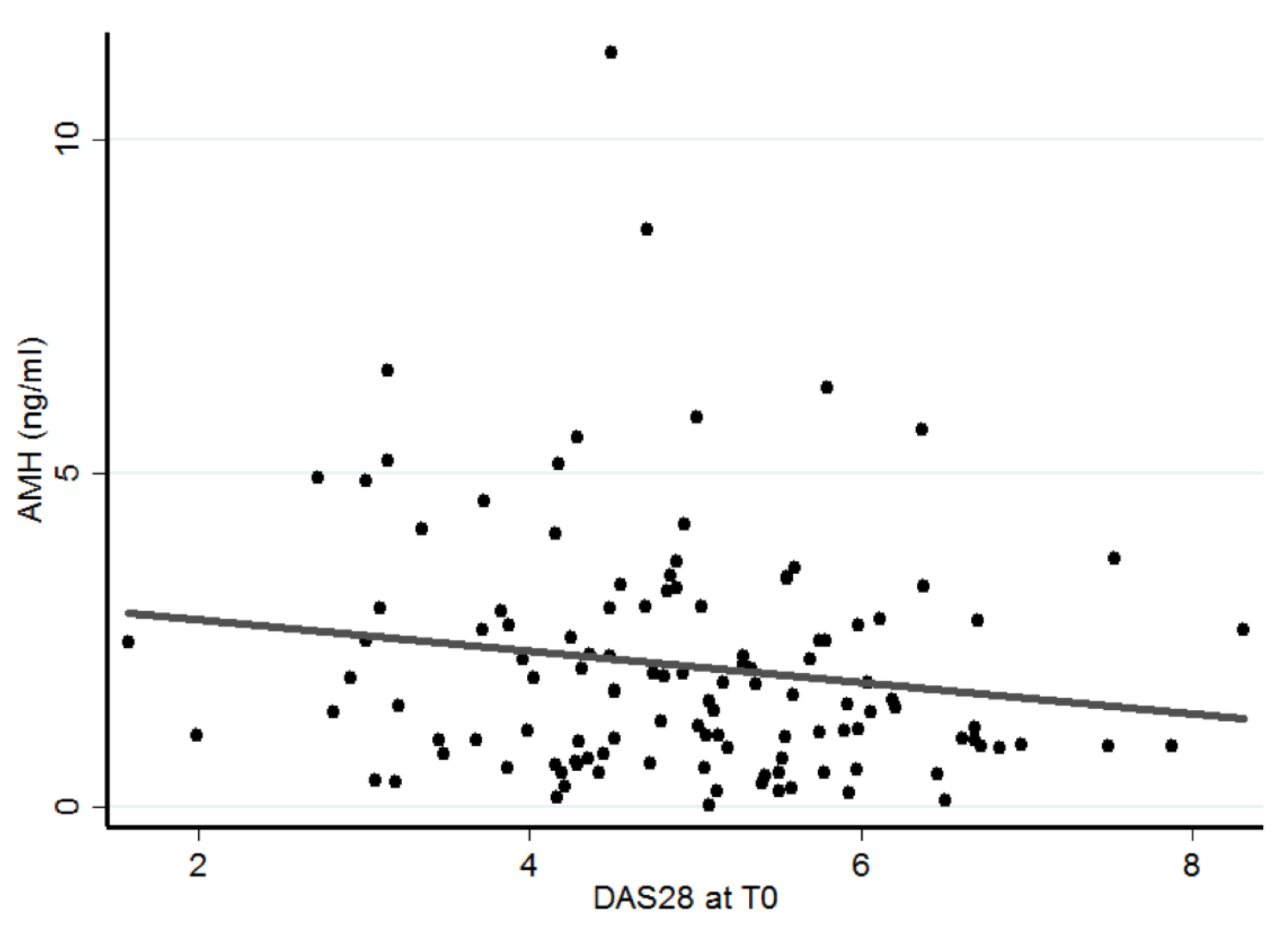

The serum AMH level at the diagnosis of the disease is negatively correlated with the DAS 28 score $(r=-0.12 ; p=0.15)$. 